\title{
AIS and VMS Ensemble Can Address Data Gaps on Fisheries for Marine Spatial Planning
}

\author{
Pascal Thoya ${ }^{1,2,3,4, * \mathbb{C} \text {, Joseph Maina }}{ }^{3}$, Christian Möllmann $^{2}$ and Kerstin S. Schiele ${ }^{1}$ \\ 1 Leibniz Institute for Baltic Sea Research Warnemuende (IOW), Seestraße 15, 18119 Rostock, Germany; \\ kerstin.schiele@io-warnemuende.de \\ 2 Center for Earth System Research and Sustainability (CEN), Institute for Marine Ecosystem and Fisheries \\ Science, University of Hamburg, 22767 Hamburg, Germany; christian.moellmann@uni-hamburg.de \\ 3 Department of Earth and Environmental Sciences, Macquarie University, North Ryde, NSW 2109, Australia; \\ joseph.mbui@mq.edu.au \\ 4 Kenya Marine and Fisheries Research Institute, P.O. Box 81651, Mombasa 80100, Kenya \\ * Correspondence: pascalthoya@gmail.com
}

Citation: Thoya, P.; Maina, J.; Möllmann, C.; Schiele, K.S. AIS and VMS Ensemble Can Address Data Gaps on Fisheries for Marine Spatial Planning. Sustainability 2021, 13, 3769 https://doi.org/10.3390/su13073769

Academic Editor: Luca Bolognini

Received: 22 February 2021

Accepted: 25 March 2021

Published: 29 March 2021

Publisher's Note: MDPI stays neutral with regard to jurisdictional claims in published maps and institutional affiliations.

Copyright: (c) 2021 by the authors. Licensee MDPI, Basel, Switzerland. This article is an open access article distributed under the terms and conditions of the Creative Commons Attribution (CC BY) license (https:// creativecommons.org/licenses/by/ $4.0 /)$.

\begin{abstract}
Spatially explicit records of fishing activities' distribution are fundamental for effective marine spatial planning (MSP) because they can help to identify principal fishing areas. However, in numerous case studies, MSP has ignored fishing activities due to data scarcity. The vessel monitoring system (VMS) and the automatic identification system (AIS) are two commonly known technologies used to observe fishing activities. However, both technologies generate data that have several limitations, making them ineffective when used in isolation. Here, we evaluate both datasets' limitations and strengths, measure the drawbacks of using any single dataset and propose a method for combining both technologies for a more precise estimation of the distribution of fishing activities. Using the Baltic Sea and the North Sea-Celtic Sea regions as case studies, we compare the spatial distribution of fishing effort from International Council for the Exploration of the Seas (ICES) VMS data and global fishing watch AIS data. We show that using either dataset in isolation can lead to a significant underestimation of fishing effort. We also demonstrate that integrating both datasets in an ensemble approach can provide more accurate fisheries information for MSP. Given the rapid expansion of MSP activities globally, our approach can be utilised in data-limited regions to improve cross border spatial planning.
\end{abstract}

Keywords: vessel monitoring system (VMS); automatic identification system (AIS); marine spatial planning; data coverage; fishing effort

\section{Introduction}

Increasing demand for marine ecosystem services globally has led to increased pressure on marine ecosystems and competition for space among various marine uses [1,2]. To address the effects of pressures on marine areas, managers are considering more holistic management approaches to managing maritime spaces [3]. Marine spatial planning (MSP) is one of the main tools for a holistic management of marine resources. MSP involves allocating marine space for different uses considering the areas' suitability, impacts on the environment and possible conflicts between activities [4]. MSP is a data-intensive process, for which outcomes are susceptible to the inherent data uncertainties. Among the steps for implementing MSP [4], defining and analysing the existing and future conditions requires high-resolution spatio-temporal data on the various marine uses [5].

Fisheries are among the marine uses with the most spatially extensive and temporally heterogeneous pattern. However, there has been some deficiency in the coverage of fisheries issues in MSP partly due to the unavailability of fisheries spatial data [6]. In regions where MSP is being developed or implemented, spatial planners have mostly relied on the vessel monitoring system (VMS), logbook data $[7,8]$ or used qualitative methods 
such as interviews and participatory mapping to identify principal fishing areas [9]. The advantages of using VMS over other methods is that it is often mandatory for fishing vessels operating in national waters to have VMS. As a result, VMS data are usually very consistent. When combined with logbook data, VMS provides a reliable estimate of the spatio-temporal distribution of fishing activities [10-12]. However, VMS has several challenges such as high installation costs, and encryption of the VMS signals, which means that only the government agencies can access the data. Additionally, the low VMS data broadcasting frequency makes it challenging to identify fishing activities at a finer spatiotemporal scale $[11,13,14]$. Overall, these challenges have made it difficult to deploy VMS as a tool for measuring fishing effort data in many parts of the world [15].

The recent advent of the automatic identification system (AIS) for mapping fishing effort distributions has provided an opportunity to fill the existing gaps in spatial fisheries data for MSP. AIS was initially introduced by the International Maritime Organization (IMO) to support marine safety, i.e., avoiding ship collisions by broadcasting vessel position and other information to nearby vessels. AIS provides information on vessel positioning, which can be used to map fishing activity independently [16,17] or together with VMS/logbook data [13]. Recent analysis indicates that there is high potential for AIS to be a primary source of mapping fishing effort globally. Its main advantages are low costs and ease of accessibility compared to VMS data [15,17].

VMS and AIS differ in several ways: the mode and frequency of satellite signal transmission, the coverage of the fishing vessels and the accessibility of data. VMS signals are transmitted from the vessels to ground stations only. In contrast, AIS signals can be received by other ships nearby, by ground stations and by satellites [15]. Additionally, AIS has a high-frequency vessel position transmission with a current average of about $30 \mathrm{~s}$ in some regions [14,15]. Consequently, the data is highly temporally resolved and better suited for mapping fishing effort compared to VMS. The main shortcoming of AIS is that it is not mandatory for smaller vessels $<300 \mathrm{GT}$. IMO only requires a mandatory AIS installation for vessels exceeding 300 GT. Additionally, larger vessels sometimes intentionally switch off the AIS for safety purposes, such as preventing piracy, and some areas do not have good AIS receptions, especially far from harbours $[13,15]$. Some countries have also adopted the use of AIS for vessels operating in their national jurisdiction. For example, since 2014, the EU has required vessels with a length of $>15 \mathrm{~m}$ to be equipped with AIS. For VMS, the rules also depend on national laws. For example, in the EU, it is a requirement for fishing vessels with a length of $>12 \mathrm{~m}$ to be equipped with VMS [18].

Evidently, both VMS and AIS have strengths and weaknesses. Combining both data sources to leverage their strength and reduce uncertainties inherent in either system would strongly benefit a more precise analysis of fisheries patterns as a basis for MSP. The integration of the VMS and AIS data can be achieved in several ways. For example, AIS datasets could provide spatial data where VMS data are not available due to proprietary issues. Additionally, VMS data can be used to fill the gaps of AIS data in areas where there is low AIS satellite coverage, e.g., in areas further offshore, while AIS could be used to improve the temporal coverage of the fishing positions [13,14,19]. However, these integration mechanisms have not been implemented at large spatial scales to facilitate regional studies.

In this study, first, we investigate the possible discrepancies between VMS data provided by the International Council for the Exploration of the Seas (ICES) and the AIS data provided by Global Fishing Watch (GFW) for mapping the distribution of fishing effort at a regional level, with the Baltic Sea and North Sea-Celtic Sea regions as case studies. We test for differences in spatio-temporal patterns of the ICES VMS and GFW AIS and compare the results from the two regions. Second, based on the identified discrepancies, we suggest a method for correcting potential errors in the estimates of fishing effort. Lastly, we quantify the discrepancies when ICES VMS and GFW AIS are used in isolation compared to a combination of the two datasets. 


\section{Material and Methods}

\subsection{Data}

Our study focuses on the Baltic Sea and the greater North Sea-Celtic Seas regions (Figure 1), where we were able to access long term VMS and AIS datasets. These datasets have been crucial for the development of MSP, as countries are required to produce marine spatial plans by 2021 [20].

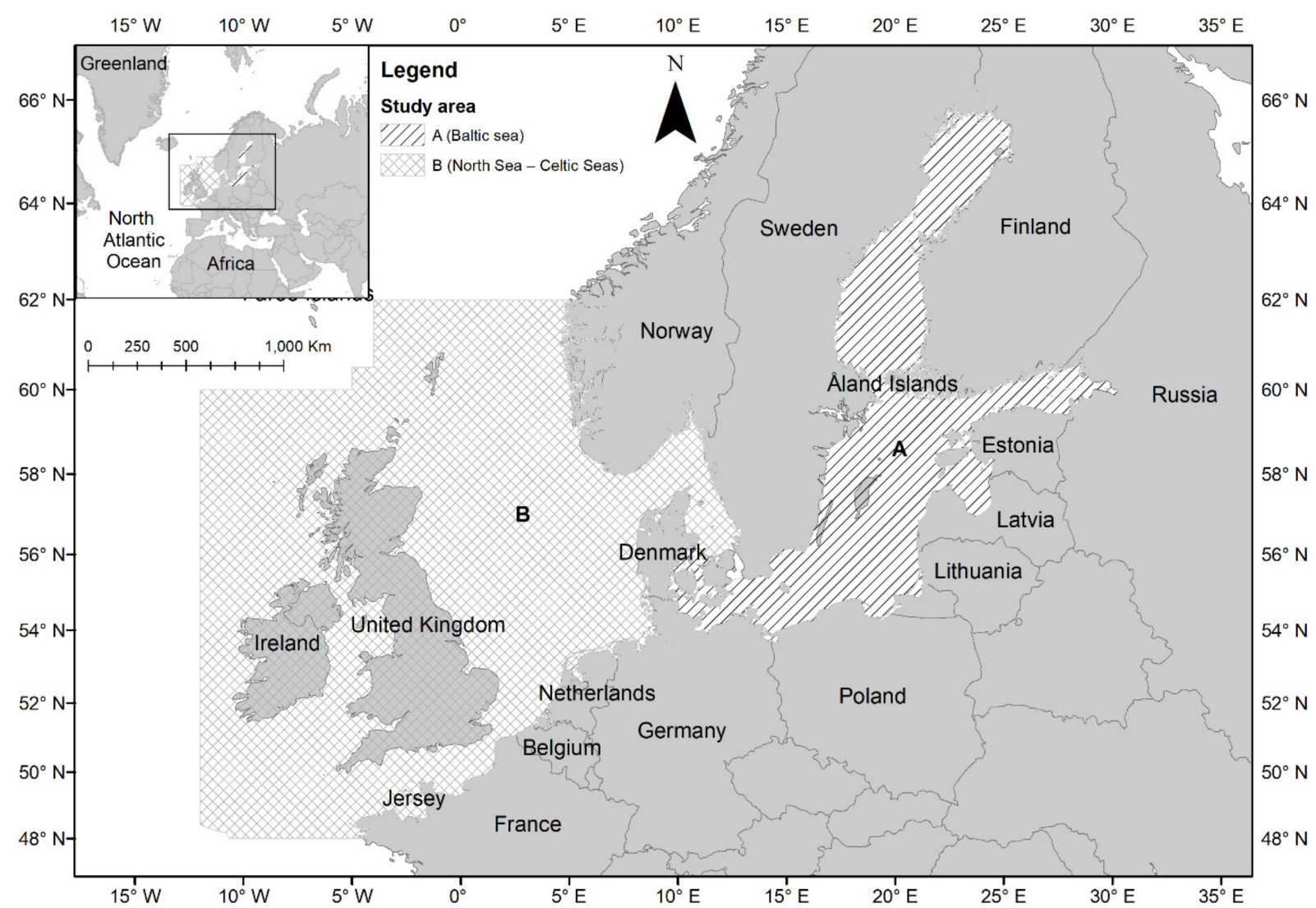

Figure 1. Map of the study area, indicating the Baltic Sea (A) and the North Sea-Celtic Seas region (B).

\subsubsection{ICES VMS Data}

VMS is a satellite-based monitoring system that consists of a GPS receiver coupled with a communication device. Logbooks are records of catch and effort. Usually, VMS and logbook data are combined to estimate fishing effort, but they are independent. The system is usually established by national governmental authorities or Regional Fisheries Management Organizations (RFMOs) for control and surveillance purposes. The system uses GPS technology to broadcast vessel positions to encrypted databases at authorities monitoring them. In the Baltic Sea and the North Sea regions, VMS data are archived and analysed by ICES [21].

We obtained processed VMS data for the period 2012-2017 from the ICES website (http:/ / www.ices.dk, accessed 15 May 2019). For the Baltic Sea, we used data from the Baltic Marine Environment Protection Commission (HELCOM) regions (ver.2, 22 January 2019); ICES data product release, http:/ / doi.org/10.17895/ices.data.4684, accessed 15 May 2019. For the North Sea-Celtic Seas region, we used data from the Convention for the Protection of the Marine Environment of the North-East Atlantic (OSPAR commission) regions II and III (ver. 2, 22 January 2019) http:/ / doi.org/10.17895/ices.data.4686, accessed 15 May 2019. The spatial data layers represent estimated fishing intensities/pressures by fishing métier, at a resolution of c-squares $(0.05 \times 0.05$ degrees $)$. For uniformity with the AIS data, the VMS fishing effort was converted to a resolution of $10 \mathrm{~km}$ degrees by 
summing up the original $0.05^{\circ} \times 0.05^{\circ}$ grids within each of the $10 \mathrm{~km}$ grids. We combined the fishing effort data for all available métiers.

\subsubsection{GFW AIS Data}

AIS data for the period 2012-2017 was obtained from the GFW website (https:/ / globalfishingwatch.org, accessed 15 May 2019). The spatial dataset contains estimated fishing intensities (hrs) at a resolution of $10 \mathrm{~km}$ grid cells. We combined the fishing effort data for all available métiers. The analysis included merging CSV files, mapping the global data set, clipping it to the study area, and gridding the data to $10 \mathrm{~km}$ grids in ArcGIS 10.5.

Unlike previous studies $[13,14]$, we did not analyse raw VMS and AIS datasets but already processed and publicly accessible datasets that are easy to acquire and often utilised in MSP processes.

\subsection{Spatio-Temporal Variation in VMS and AIS Data}

To evaluate the degree of discrepancy between ICES VMS and GFW AIS data for mapping fishing effort in the Baltic Sea and the North Sea-Celtic Sea regions, we used the SPAtial EFficiency metric (SPAEF) introduced by [22]. SPAEF is a multi-composite and statistical metric that considers the differences in co-location, variation and distribution patterns. It robustly evaluates similarities in spatial patterns [22,23]. SPAEF values range from $0-1$, with 1 being the highest spatial similarity between the spatial distributions.

SPAEF is calculated as

$$
S P A E F=1-\sqrt{(\alpha-1)^{2}+(\beta-1)^{2}+(\gamma-1)^{2}}
$$

where

$\alpha$-is the correlation coefficient between the ICES VMS grid values and GFW AIS grid values $\beta$-is the coefficient of variation for ICES VMS grid values divided by the coefficient of variation for GFW AIS grid values, and

$\gamma$-is the match of the histograms of the ICES VMS and GFW AIS grid values.

\subsection{ICES VMS—GFW AIS Ensemble}

Our approach to developing an AIS-VMS ensemble focused on the availability of AIS and VMS data. VMS and AIS have different limitations and strengths (Table 1). An ensemble of these datasets is expected to enhance spatial fisheries data accuracy and coverage [13-15]. Low availability of AIS data is mostly caused by inadequate AIS satellite coverage and deactivation of the AIS transmitter by the fishing vessels in areas where AIS use is not required by law. VMS data availability is low in areas where the system has not been installed or where data is not available due to proprietary issues. Hence, in areas where either VMS or AIS is lacking, the datasets' combination can help improve the overall spatial data coverage.

It is important to note that the GFW AIS and ICES VMS fishing intensities are estimated with different methodologies $[17,24]$. We argue that, although the ICES VMS and GFW AIS data are computed differently, the ratio of the two datasets should be the same in the grid cells where both ICES VMS and GFW AIS were recorded as they represent fishing effort for the same vessels. We use the relationship to compute the fishing effort in the cells where either ICES VMS or GFW AIS was missing, similar to the geographic ratio analysis suggested by [25]. 
Table 1. Strength and weaknesses of automatic identification system (AIS) and vessel monitoring system (VMS) datasets (adopted from [13-15]).

\begin{tabular}{llll}
\hline & \multicolumn{1}{c}{ VMS } & \multicolumn{1}{c}{ AIS } \\
\hline Strengths & $\begin{array}{l}\text { High vessels coverage as it is mandatory to use } \\
\text { for fishing vessels in some jurisdictions with } \\
\text { penalties for switching off } \\
\text { Good signal reception in most places and hence } \\
\text { consistent data availability }\end{array}$ & $\begin{array}{l}\text { High confidence for identifying vessels and } \\
\text { their fishing activity due to the availability of } \\
\text { logbook data }\end{array}$ & $\begin{array}{l}\text { High temporal frequency of fishing } \\
\text { Opesition data } \\
\text { Open-source data, easily accessible } \\
\text { to the public }\end{array}$ \\
\hline Weaknesses & $\begin{array}{l}\text { Low temporal frequency of fishing position } \\
\text { affecting the estimation of fished area } \\
\text { Data availability is restricted to specific } \\
\text { national agencies }\end{array}$ & $\bullet$ & $\begin{array}{l}\text { Low vessels coverage as it is not } \\
\text { mandatory for use by fishing vessels } \\
\text { Low signal reception in some areas } \\
\text { and hence inconsistent data }\end{array}$ \\
\hline
\end{tabular}

We calculated the ratio of VMS and AIS for each grid cell and averaged the ratios to obtain the overall VMS to AIS ratio for each year, as shown in Equation (2), where $E_{(\text {ratio })}$ is the overall ratio for the year, $\mathrm{E}_{\mathrm{VMS}}$ is the VMS fishing effort (hrs) for the grid cell, $\mathrm{E}_{(\mathrm{AIS})}$ is the AIS fishing effort for the grid cell, and $\mathrm{N}$ is the number of grid cells that had both AIS and VMS data for that year.

$$
E_{(\text {ratio })}=\frac{\sum_{i=1}^{N}\left(\frac{E_{(V M S)}}{E_{(A I S)}}\right)}{\mathrm{N}}
$$

In areas where there was either ICES VMS or GFW AIS only, we used the $E_{(\text {ratio })}$ to derive ICES VMS or GFW AIS, as shown in Equation (3) where $D_{(V M S)}$ denotes the derived VMS values. The final ensemble layer was created by merging the original VMS layer with derived VMS values.

$$
D_{(V M S)}=E_{(A I S)} * E_{(\text {ratio })}
$$

\section{Results}

\subsection{Spatio-Temporal Variations in ICES VMS and GFW AIS Data}

We identified discrepancies in the spatial-temporal coverage of fishing activities by the VMS and AIS datasets. In the Baltic Sea, in the early years (2012 and 2013), VMS data displayed high spatial coverage of fishing areas with fishing effort covering about $96 \%$ of the study area and decreasing to about $48 \%$ of the study area between 2014 and 2016 (Figure 2).

In contrast, AIS data had a low spatial coverage in 2012, covering approximately $43 \%$ of the study area, but steadily gained coverage of fishing areas, covering $95 \%$ of the study area in 2016. The ensemble data filled the VMS data gaps between 2014-2016 and restored the distribution similar to values in 2012. The ensemble fishing effort data suggests fishing activities over the entire Baltic Sea with fishing hotspots in the Kattegat and Western Baltic. The most apparent discrepancies are in the northern Baltic, which has only VMS data in 2012 and only AIS data in 2016 (Figure 2). 


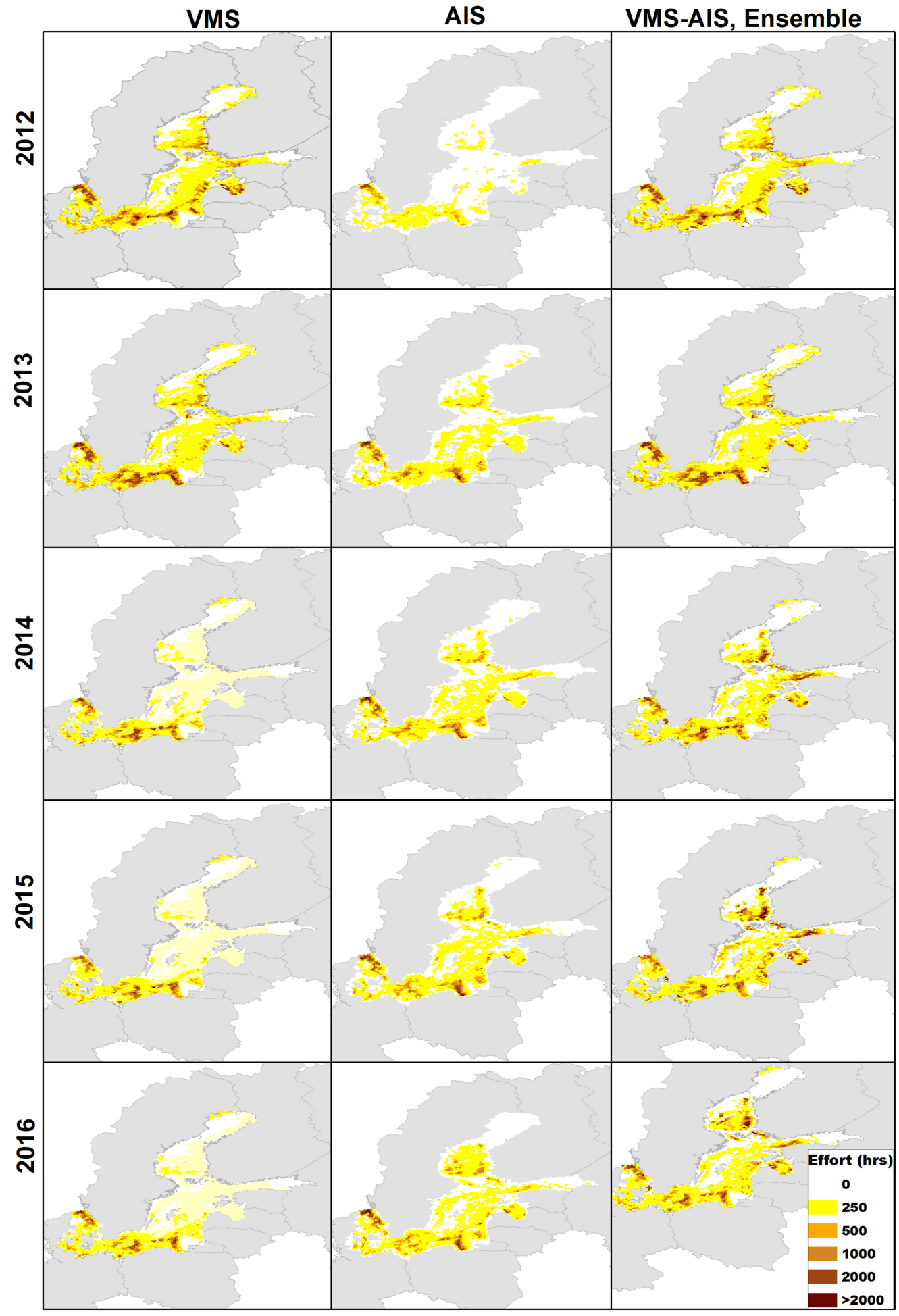

Figure 2. Spatial distribution of fishing effort (hrs) in the Baltic Sea between 2012 and 2016, using VMS and AIS datasets.

For the North Sea-Celtic Seas region, the VMS and AIS datasets mainly show discrepancies in 2012 and 2013, where AIS shows lower coverage than VMS (Figure 3). The ensemble datasets also show fishing activities distributed in the whole study area. Fishing hotspots were evident near the coasts of France, Belgium and the Netherlands, as well as the United Kingdom and the English Channel (Figures 3 and 5). 


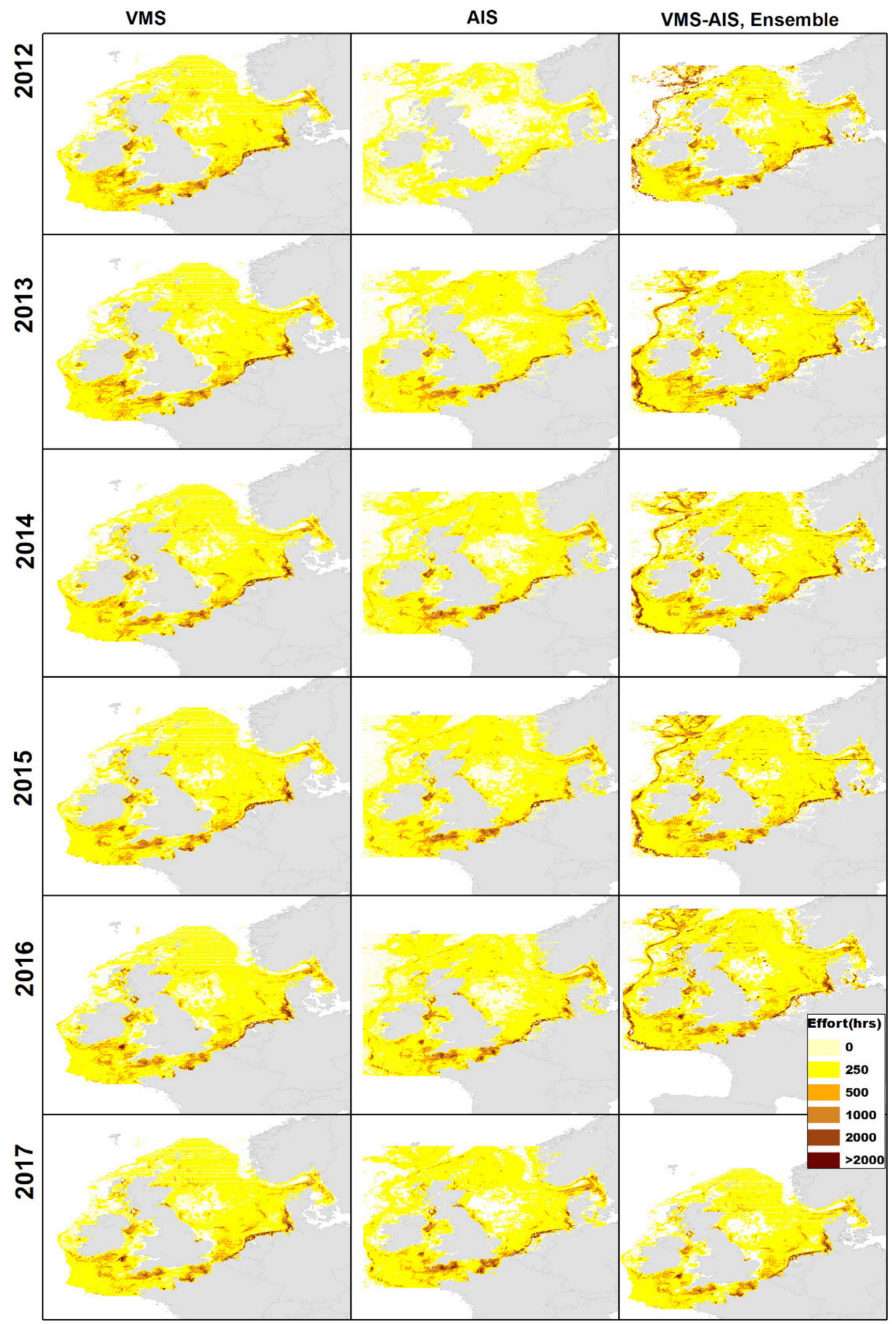

Figure 3. Spatial distribution of fishing effort (hrs) in the North Sea-Celtic Seas region between 2012 and 2017 using VMS and AIS datasets.

We found some variation in the SPAEF coefficient between annual VMS and AIS datasets between the Baltic Sea and the North Sea-Celtic Sea. Higher SPAEF coefficient was found for the North Sea-Celtic Sea (mean value 0.64), compared to the Baltic Sea (mean value 0.43 ) over the study period. Higher SPAEF coefficients indicate that the VMS and AIS were more similar in the North Sea-Celtic Sea region than in the Baltic Sea. Additionally, the SPAEF coefficient varied between the years. For the Baltic Sea, the lowest SPAEF value was found for 2012 and the highest for 2013. For the North Sea-Celtic Sea region, we derived the lowest SPAEF value for 2012 and the highest in 2015 (Figure 4). 


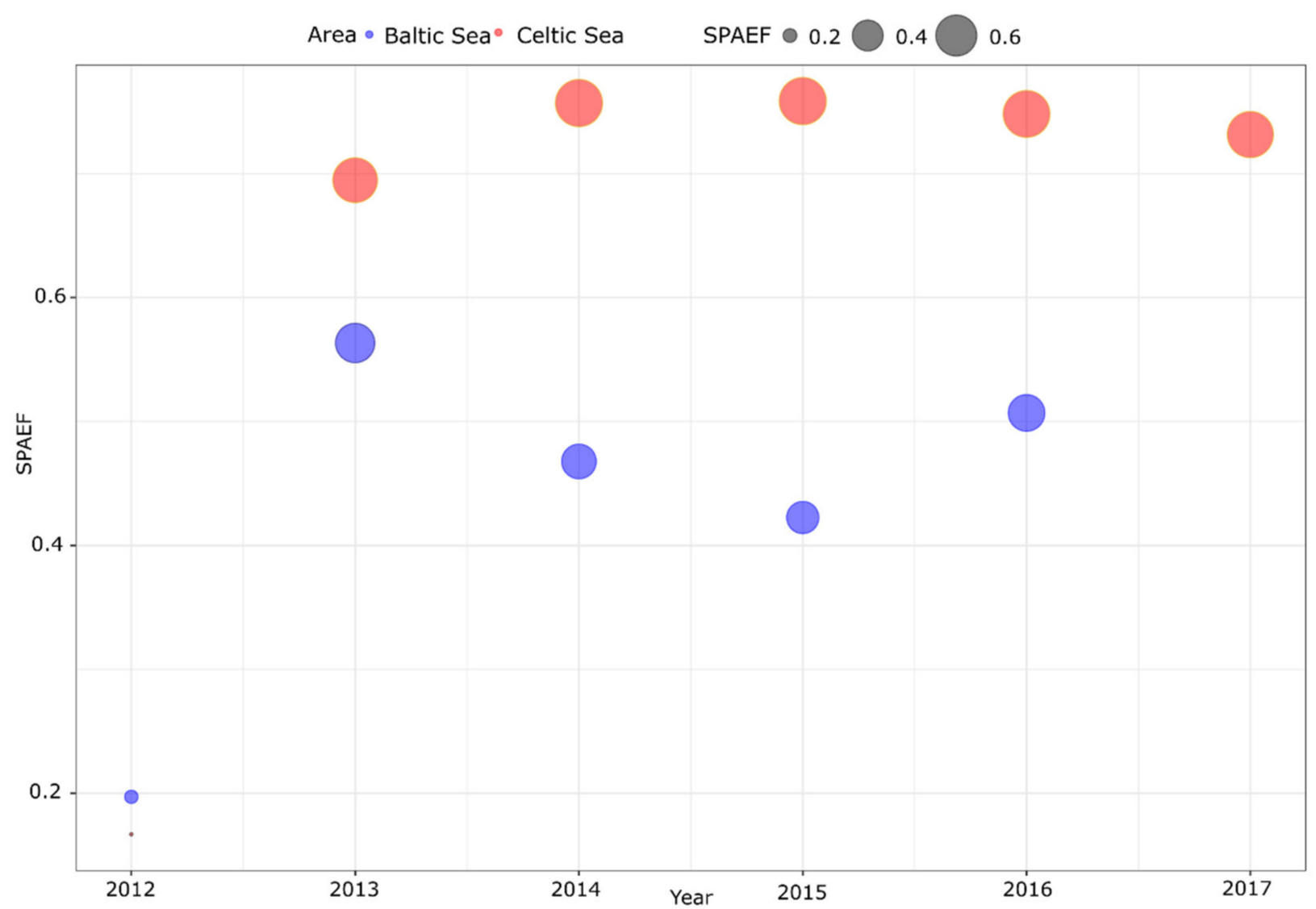

Figure 4. SPAEF values indicating the similarities of spatial patterns of the International Council for the Exploration of the Seas (ICES) VMS and GFW AIS data for the Baltic Sea and North Sea-Celtic Sea regions.

\subsection{Underestimation of ICES VMS and GFW AIS Data}

Our results indicate that when either VMS or AIS is used in isolation, there is an underestimation of fishing effort levels in the Baltic Sea and the North Sea-Celtic Sea regions. The levels of underestimation of fishing effort vary across the years and between the regions. For the Baltic Sea, there is a decreasing trend of underestimation of fishing activities by the AIS data over the years, while underestimation by VMS data is increasing. Similarly, there is a decreasing trend of underestimating fishing activities by the AIS data for the North Sea-Celtic Sea region over the years. However, the precision of VMS data is almost constant (Figure 5).

Additionally, Figure 5 depicts the total fishing effort's temporal trends when both the ICES VMS Data and GFW AIS data are combined to create an ensemble. Despite variations in both VMS and AIS datasets between 2012 and 2017, the computed ensemble data shows that the total fishing effort remained relatively constant during the same study period in the North Sea-Celtic Sea region, while the Baltic Sea region shows a decreasing trend over the years (Figure 5). 


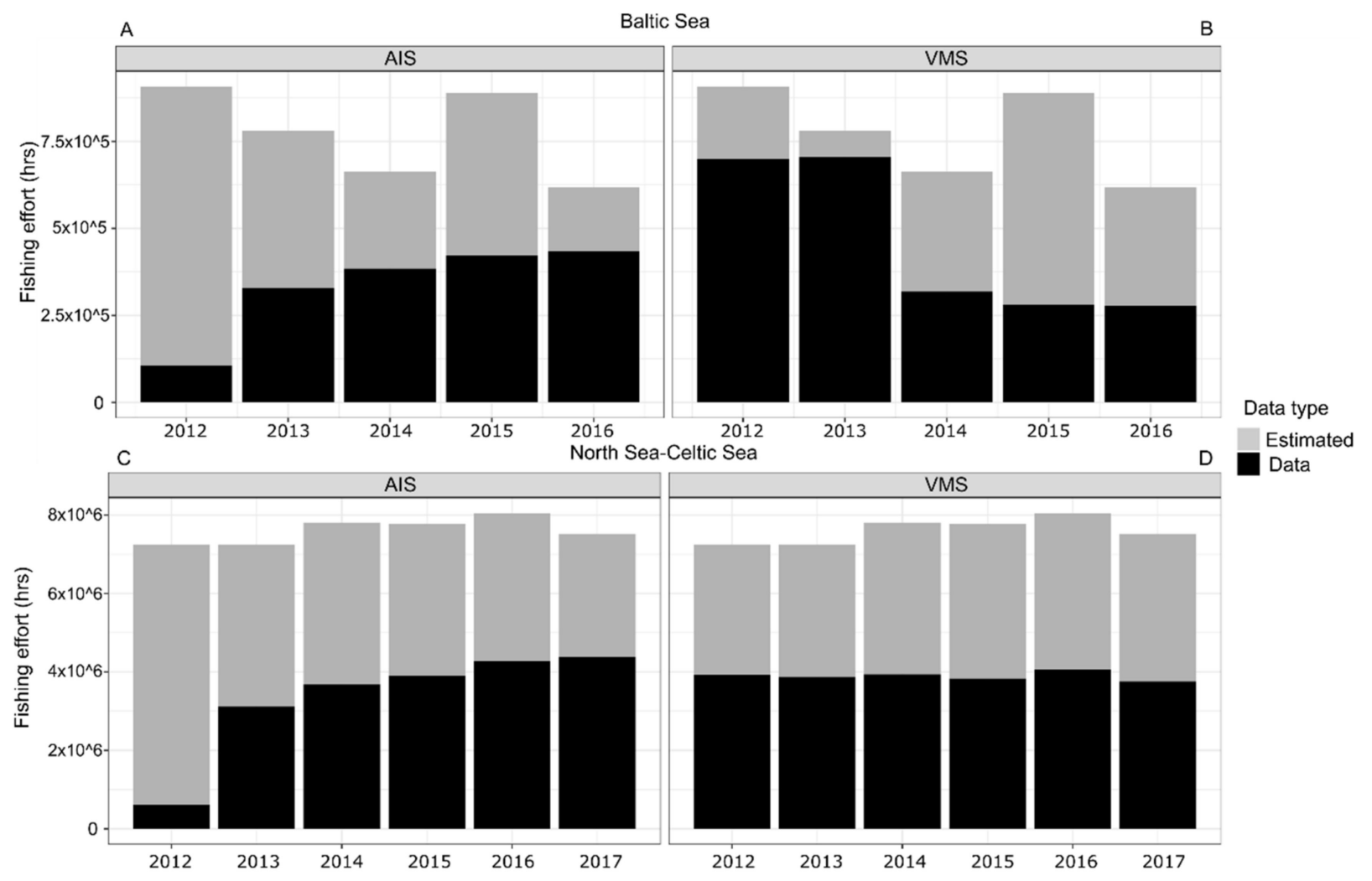

Figure 5. Total calculated fishing effort (hrs) in both study regions using the ensemble approach. Estimated data is the data derived in an area where either VMS or AIS data was missing.

\section{Discussion}

We investigate the discrepancies in spatio-temporal patterns of the ICES VMS and GFW AIS datasets and the potential underestimation of fishing activities when either VMS or AIS datasets are used alone to map fishing effort. The study's overall goal is to present a dataset that will show the accurate picture of the fishing effort distribution to provide more reliable data for the MSP process, especially at a regional level. We achieved our goal by inspecting the relationship between the VMS data and AIS data, interpolating this relationship for grid cells where one of the datasets was missing and creating an ensemble dataset. Such an approach is beneficial in MSP processes as it provides better evidence of fishing effort distribution.

Our findings show spatial similarities and differences between the VMS and AIS datasets in the Baltic Sea and North Sea-Celtic Sea regions. Although the VMS data and AIS datasets are computed differently, their remarkable similarity, especially in the North Sea-Celtic Sea region, indicates that the two datasets represent similar fishing effort. However, the ensemble data generally indicate an underestimation for both VMS data and AIS data. Our results confirmed that the ensemble data improve the spatial representation of fishing effort by VMS and AIS. Thus, the suggested ensemble method offers a solution for improving spatial fisheries datasets compared to a single use of either VMS or AIS data.

There are several possible explanations for the spatial-temporal discrepancies and underestimation of the VMS and AIS datasets. The large increase in AIS data in both the Baltic Sea and the North Sea areas between 2012 and 2014 may result from the improved adoption of AIS after the EU passed the law for the mandatory AIS installation for vessels of $>15 \mathrm{~m}$. Additionally, AIS data may suffer from poor signal receptions, especially in the area further offshore. On the other hand, the displayed low VMS data coverage observed between 2015 and 2017 in the Baltic Sea could have resulted from the non-submission of VMS data to ICES by countries in the regions [13-15,26]. Our finding of a close resemblance of annual patterns of fishing activities presented by VMS and AIS data in the North Sea- 
Celtic Sea area as indicated by the SPAEF values is similar to recent studies in nearby regions that found a close relationship between VMS and AIS datasets in the neighbouring regions of the Bay of Biscay and Northeast Atlantic $[27,28]$. The close relationship between the VMS and AIS in the studies mentioned above was attributed to VMS's mandatory requirement for fishing vessels and high coverage of AIS in vessels of $>15 \mathrm{~m}$ in this region.

The ensemble data approach is especially relevant in data-poor regions where MSP and conservation and planning efforts are sometimes forced to use proxies to fill data gaps $[29,30]$. Although the Baltic Sea area is considered to have adequate coverage of both VMS and AIS, the ICES website's accessed data had some gaps. Interestingly, VMS data alone in the area suggest reduced fishing activities in the Northern Baltic Sea areas during 2014-2016, a result not supported by AIS data during the same period. The computed ensemble data gives a better representation of the fishing effort activities of the area. The ensemble data have also provided an opportunity to redefine long-term fisheries spatial data estimates for the study area and give a more comprehensive spatial-temporal account of the spatial distribution of fishing effort than what is currently available to the public. The HELCOM map data service http:/ / maps.helcom.fi/website/mapservice/, accessed 15 May 2019, which covers the study area, is one of the main sources of MSP data utilised by MSP stakeholders. This data displays the same fishing effort with the data gaps as described in this paper. Our study indicates a considerable under-estimation of fishing effort activities when this dataset is used, and its inclusion in decision-making processes such MSP could hence be misleading. Additionally, to continue using this dataset for management purposes, our study helped understand its effectiveness in mapping fishing effort and what proportion of the fishing activities may be omitted.

The MSP process presents potential benefits to the fisheries sector, e.g., protecting crucial fisheries areas such as spawning and nursery grounds. However, several limitations to fisheries can also arise from the MSP process, such as reducing fishing space, modifying fishing behaviours and loss of revenue [1]. Proper integration of fisheries in MSP depends on the availability of adequate spatial data on fisheries [31]. In some cases, fisheries data limitation has hindered the MSP processes in two steps: analysing existing conditions and planning for future activities. Ultimately, this has led to fisheries' omission in the spatial plans [6,30]. Several decision-support tools and algorithms have been developed with a good capacity of informing MSP. The ability of these tools to produce useful results is dependent on good spatial and temporal information [30,32,33]. Lack of spatial fisheries data may be inevitable in some areas due to confidentiality and lack of coverage. Our approach of combining AIS and VMS improves fisheries spatial datasets' quality and can enhance MSP decision support tools' performance and ultimately improve MSP processes.

Our study utilised datasets from open sources with several limitations, such as nonsubmission of data and poor signals. These factors create a scenario of a data-poor area and the possibility of evaluating how the VMS-AIS ensemble could improve VMS datasets in data-poor regions. However, it is important to note that the VMS datasets in national agencies' custody may have a better quality that could be close to the one achieved by the proposed ensemble.

Eventually, our results show that combining VMS and AIS datasets greatly improved coverage in areas where differences existed and exposed the risk of fishing effort underestimation when VMS and AIS datasets are used singly. The proposed method presents an approach that could be utilised for effective cross border MSP in areas where data limitations exist.

Author Contributions: Conceptualization, P.T., J.M., C.M. and K.S.S.; methodology, P.T.; software, P.T.; validation, P.T., J.M., C.M. and K.S.S.; formal analysis, P.T.; investigation, P.T.; resources, J.M., C.M. and K.S.S. data curation, P.T.; writing—original draft preparation, P.T., J.M., C.M. and K.S.S.; writing-review and editing, P.T., J.M., C.M. and K.S.S.; visualization, P.T., J.M., C.M. and K.S.S.; supervision, J.M., C.M. and K.S.S.; project administration, K.S.S.; funding acquisition, J.M., C.M. and K.S.S. All authors have read and agreed to the published version of the manuscript. 
Funding: This work is partly funded by the Kenyan-German Post Graduate program, Macquarie university higher education research funding and the BONUS BASMATI project. BONUS BASMATI is supported by BONUS (Art. 185), funded jointly by the EU, Forschungs Zentrum Jülich GmbH, Germany and other national funding agencies.

Institutional Review Board Statement: Not applicable.

Informed Consent Statement: Informed consent was obtained from all subjects involved in the study.

Data Availability Statement: The datasets can be accessed at the GFW and ICES websites.

Acknowledgments: The publication of this article was funded by the Open Access Fund of the Leibniz Association.

Conflicts of Interest: The authors declare no conflict of interest.

\section{References}

1. Bastardie, F.; Nielsen, J.R.; Eigaard, O.R.; Fock, H.; Jonsson, P.; Bartolino, V. Competition for marine space: Modelling the baltic sea fisheries and effort displacement under spatial restrictions. ICES J. Mar. Sci. 2015, 72, 824-840. [CrossRef]

2. Halpern, B.S.; Walbridge, S.; Selkoe, K.A.; Kappel, C.V.; Micheli, F.; D’agrosa, C.; Bruno, J.F.; Casey, K.S.; Ebert, C.; Fox, H.E. A global map of human impact on marine ecosystems. Science 2008, 319, 948-952. [CrossRef] [PubMed]

3. Gee, K.; Kannen, A.; Heinrichs, B. Baltic Sea Plan Vision 2030: Towards the Sustainable Planning of Baltic Sea Space; BalticSeaPlan: Hamburg, Germany, 2011.

4. Ehler, C.; Douvere, F.; Intergovernmental Oceanographic Commission. Marine Spatial Planning Programme: A Step-by-Step Approach toward Ecosystem-Based-Management; UNESCO: Paris, France, 2009.

5. Eastwood, P.; Mills, C.; Aldridge, J.; Houghton, C.; Rogers, S. Human activities in UK offshore waters: An assessment of direct, physical pressure on the seabed. ICES J. Mar. Sci. 2007, 64, 453-463. [CrossRef]

6. Fock, H.O. Fisheries in the context of marine spatial planning: Defining principal areas for fisheries in the German EEZ. Mar. Policy 2008, 32, 728-739. [CrossRef]

7. Campbell, M.S.; Stehfest, K.M.; Votier, S.C.; Hall-Spencer, J.M. Mapping Fisheries for marine spatial planning: Gear-specific Vessel Monitoring System (VMS), marine conservation and offshore renewable energy. Mar. Policy 2014, 45, 293-300. [CrossRef]

8. Shucksmith, R.; Gray, L.; Kelly, C.; Tweddle, J.F. Regional marine spatial planning-The data collection and mapping process. Mar. Policy 2014, 50, 1-9. [CrossRef]

9. Turner, R.A.; Polunin, N.V.; Stead, S.M. Mapping inshore fisheries: Comparing observed and perceived distributions of pot fishing activity in Northumberland. Mar. Policy 2015, 51, 173-181. [CrossRef]

10. Amoroso, R.O.; Pitcher, C.R.; Rijnsdorp, A.D.; McConnaughey, R.A.; Parma, A.M.; Suuronen, P.; Eigaard, O.R.; Bastardie, F.; Hintzen, N.T.; Althaus, F. Bottom Trawl fishing footprints on the World's Continental Shelves. Proc. Natl. Acad. Sci. USA 2018, 115, E10275-E10282. [CrossRef]

11. Hintzen, N.T.; Bastardie, F.; Beare, D.; Piet, G.J.; Ulrich, C.; Deporte, N.; Egekvist, J.; Degel, H. VMStools: Open-source software for the processing, analysis and visualisation of fisheries logbook and VMS Data. Fish. Res. 2012, 115, 31-43. [CrossRef]

12. Russo, T.; D'Andrea, L.; Parisi, A.; Cataudella, S. VMSbase: An R-package for VMS and logbook data management and analysis in fisheries ecology. PLoS ONE 2014, 9, e100195. [CrossRef] [PubMed]

13. Russo, T.; D’andrea, L.; Parisi, A.; Martinelli, M.; Belardinelli, A.; Boccoli, F.; Cignini, I.; Tordoni, M.; Cataudella, S. Assessing the fishing footprint using data integrated from different tracking devices: Issues and opportunities. Ecol. Indic. 2016, 69, 818-827. [CrossRef]

14. Shepperson, J.L.; Hintzen, N.T.; Szostek, C.L.; Bell, E.; Murray, L.G.; Kaiser, M.J. A comparison of VMS and AIS data: The effect of data coverage and vessel position recording frequency on estimates of fishing footprints. ICES J. Mar. Sci. 2018, 75, 988-998. [CrossRef]

15. Taconet, M.; Kroodsma, D.; Fernandes, J.A.; Kramer, S. Global Atlas of AIS-Based Fishing Activity—Challenges and Opportunities; FAO: Rome, Italy, 2019.

16. Ferrà, C.; Tassetti, A.N.; Grati, F.; Pellini, G.; Polidori, P.; Scarcella, G.; Fabi, G. Mapping change in bottom trawling activity in the Mediterranean Sea through AIS data. Mar. Policy 2018, 94, 275-281. [CrossRef]

17. Kroodsma, D.A.; Mayorga, J.; Hochberg, T.; Miller, N.A.; Boerder, K.; Ferretti, F.; Wilson, A.; Bergman, B.; White, T.D.; Block, B.A. Tracking the global footprint of fisheries. Science 2018, 359, 904-908. [CrossRef] [PubMed]

18. European Commison. Council Regulation (EC) No. 1224/2009 of 20 November 2009 Establishing a Community control system for ensuring compliance with therules of the Common Fisheries Policy, amending Regulations (EC) No. 847/96, (EC) No 2371/2002, (EC) No. 811/2004, (EC) No. Off. J. Eur. Union 2009, L343, 1-50.

19. Malarky, L.; Lowell, B. Avoiding detection: Global case studies of possible AIS avoidance. Oceana. Available online: https: / / usa.oceana.org/publications/reports/avoiding-detection-global-case-studies-possible-ais-avoidance (accessed on 15 May 2019). 
20. European Comission. EC Directive 2014/89/EU of the European Parliament and of the Council of 23 July 2014 Establishing a Framework for Maritime Spatial Planning; European Comission: Strasbourg, France, 2018.

21. ICES Advisory Committee. ICES OSPAR Request for Further Development of Fishing Intensity and Pressure Mapping; ICES: Copenhagen, Denmark, 2016.

22. Koch, J.; Demirel, M.C.; Stisen, S. The SPAtial EFficiency Metric (SPAEF): Multiple-component evaluation of spatial patterns for optimization of hydrological models. Geosci. Model Dev. 2018, 11, 1873. [CrossRef]

23. Plet-Hansen, K.S.; Bastardie, F.; Ulrich, C. The value of commercial fish size distribution recorded at haul by haul compared to trip by trip. ICES J. Mar. Sci. 2020, 77, 2729-2740. [CrossRef]

24. Eigaard, O.R.; Bastardie, F.; Breen, M.; Dinesen, G.E.; Hintzen, N.T.; Laffargue, P.; Mortensen, L.O.; Nielsen, J.R.; Nilsson, H.C.; O'Neill, F.G. Estimating seabed pressure from demersal trawls, seines, and dredges based on gear design and dimensions. ICES J. Mar. Sci. 2016, 73, i27-i43. [CrossRef]

25. Duan, Z.; Bastiaanssen, W. First Results from version 7 TRMM 3B43 precipitation product in combination with a new downscalingcalibration procedure. Remote Sens. Environ. 2013, 131, 1-13. [CrossRef]

26. Steering Group on Ecosystem Pressures and Impacts. Interim Report of the Working Group on Spatial Fisheries Data (WGSFD); ICES: Brest, France, 17-20 May 2016.

27. Fernandes, J.A.; Granado, I.; Murua, H.; Arrizabalaga, H.; Zarauz, L.; Mugerza, E.; Arregi, L.; Galparsoro, I.; Murua, J.; Iriondo, A.; et al. Bay of Biscay VMS/logbook comparison (FAO Subarea 27.8). In Global Atlas of AIS-Based Fishing Activity-Challenges and Opportunities; Taconet, M., Kroodsma, D., Fernandes, J.A., Eds.; FAO: Rome, Italy, 2019.

28. Gibin, M.S.Z.; Granado, I.; Kroodsma, D.; Miller, N.A.; Fernandes, J.A. AIS-based fishing activity in the Northeast Atlantic. In Global Atlas of AIS-Based Fishing Activity-Challenges and Opportunities; Taconet, M., Kroodsma, D., Fernandes, J.A., Eds.; FAO: Rome, Italy, 2019.

29. Ban, N.C.; Hansen, G.J.; Jones, M.; Vincent, A.C. Systematic marine conservation planning in data-poor regions: Socioeconomic data is essential. Mar. Policy 2009, 33, 794-800. [CrossRef]

30. Gissi, E.; McGowan, J.; Venier, C.; Carlo, D.D.; Musco, F.; Menegon, S.; Mackelworth, P.; Agardy, T.; Possingham, H. Addressing transboundary conservation challenges through marine spatial prioritization. Conserv. Biol. 2018, 32, 1107-1117. [CrossRef] [PubMed]

31. Janßen, H.; Bastardie, F.; Eero, M.; Hamon, K.G.; Hinrichsen, H.-H.; Marchal, P.; Nielsen, J.R.; Le Pape, O.; Schulze, T.; Simons, S. Integration of fisheries into marine spatial planning: Quo Vadis? Estuar. Coast. Shelf Sci. 2017, 201, 105-113. [CrossRef]

32. Pınarbaşı, K.; Galparsoro, I.; Borja, Á.; Stelzenmüller, V.; Ehler, C.N.; Gimpel, A. Decision support tools in marine spatial planning: Present applications, gaps and future perspectives. Mar. Policy 2017, 83, 83-91. [CrossRef]

33. Stelzenmüller, V.; Lee, J.; Garnacho, E.; Rogers, S. Assessment of a bayesian belief network-GIS framework as a practical tool to support marine planning. Mar. Pollut. Bull. 2010, 60, 1743-1754. [CrossRef] 